\title{
Stem Cells Associated with Macroporous Bioceramics for Long Bone Repair: 6- to 7-Year Outcome of a Pilot Clinical Study
}

\author{
MAURILIO MARCACCI, M.D., ${ }^{1}$ ELIZAVETA KON, M.D., ${ }^{1}$ VLADIMIR MOUKHACHEV, M.D., ${ }^{2}$ \\ ANDREI LAVROUKOV, M.D. ${ }^{2, \dagger}$ SERGEJ KUTEPOV, M.D., ${ }^{3}$ RODOLFO QUARTO, M.D., ${ }^{4, *}$ \\ MADDALENA MASTROGIACOMO, Ph.D. ${ }^{4}$ and RANIERI CANCEDDA, M.D. ${ }^{4}$
}

\begin{abstract}
Extensive bone loss is still a major problem in orthopedics. A number of different therapeutic approaches have been developed and proposed, but so far none have proven to be fully satisfactory. We used a new tissue engineering approach to treat four patients with large bone diaphysis defects and poor therapeutic alternatives. To obtain implantable three-dimensional (3D) living constructs, cells isolated from the patients' bone marrow stroma were expanded in culture and seeded onto porous hydroxyapatite (HA) ceramic scaffolds designed to match the bone deficit in terms of size and shape. During the surgical session, an Ilizarov apparatus or a monoaxial external fixator was positioned on the patient's affected limb and the ceramic cylinder seeded with cells was placed in the bone defect. Patients were evaluated at different postsurgery time intervals by conventional radiographs and computed tomography (CT) scans. In one patient, an angiographic evaluation was performed at 6.5 years follow-up. In this study we analyze the long-term outcome of these patients following therapy. No major complications occurred in the early or late postoperative periods, nor were major complaints reported by the patients. No signs of pain, swelling, or infection were observed at the implantation site. Complete fusion between the implant and the host bone occurred 5 to 7 months after surgery. In all patients at the last follow-up (6 to 7 years postsurgery in patients 1 to 3), a good integration of the implants was maintained. No late fractures in the implant zone were observed. The present study shows the long-term durability of bone regeneration achieved by a bone engineering approach. We consider the obtained results very promising and propose the use of cultureexpanded osteoprogenitor cells in conjunction with porous bioceramics as a real and significant improvement in the repair of critical-sized long bone defects.
\end{abstract}

\section{INTRODUCTION}

$\mathbf{E}$ XTENSIVE bone LOSS OR DESTRUCTION is still a major problem in orthopedics, due in large part to the lack of predictability in obtaining functional bone reconstruction. Present therapeutic approaches to repair large bone defects can be divided into two groups: excluding graft transplant (Ilizarov bone transport) or including graft transplant (autologous, homologous, or heterologous bone grafts using different biomaterial implants).

The Ilizarov technique, osteotomy followed by bone distraction, relies on the bone regeneration potential, thus avoiding

\footnotetext{
${ }^{1}$ Istituti Ortopedici Rizzoli, Bologna, Italy.

${ }^{2}$ Ural Orthopedic Research Institute, Ekaterinburg, Russia.

${ }^{3}$ Ural State Medical Academy, Ekaterinburg, Russia.

${ }^{4}$ Dipartimento di Oncologia Biologia e Genetica, Universita' di Genova \& Istituto Nazionale per la Ricerca sul Cancro, Genova, Italy. *Present address: Dipartimento di Chimica e Tecnologie Farmaceutiche ed Alimentari, Università di Genova, Italy.

${ }^{\dagger}$ Unfortunately, Dr. Lavroukov died in a car accident in summer 2005. The other coauthors wish to dedicate this manuscript to him.
} 
concerns related to graft integration, but it is highly inconvenient for the patient. ${ }^{1,2}$

Autologous bone implants are used as either nonvascularized or vascularized grafts. Implants of nonvascularized grafts are usually performed to treat small bone defects. Vascularized grafts are most commonly used for extensive bone reconstructions such as in tumor surgery, but require long and difficult surgical operations. The success rate is high, but complications such as infections and nonunions are common, especially in large shaft reconstructions. ${ }^{3-6}$ Further, large reconstructions by autologous bone require a large harvest of healthy tissue resulting in significant donor site morbidity. ${ }^{7}$ Homologous grafts from bone banks are widely used due to their availability without concerns of donor site morbidity. However, this material presents potential risk of viral or bacterial infection and possible immune response of the host tissue ${ }^{8}$ that can impair the graft integration and result in long recovery times and high rate of complications. $^{9-11}$ Moreover, the complete substitution of the cortical graft with the host bone is not achieved, and it eventually often results in the late graft fracture. ${ }^{12}$

Different biomaterials have been proposed as bone substitutes with conflicting results. Among these, hydroxyapatite (HA) and other calcium phosphate ceramics have shown the most promising results due to their osteoconductive properties, unlimited availability, and absence of immune response and risk of virus transmission. ${ }^{13-16}$ The main difficulty to their wider use remains the absence of osteoinductive properties, thus limiting their application to repairing large segmental bone loss.

Tissue engineering has been proposed as an alternative to the traditional techniques in repairing bone defects. ${ }^{8,17-24}$ The general principle of tissue engineering involves the association of cells with a natural or synthetic support, or scaffold, to produce a three-dimensional (3D) living, implantable construct. Among the different biomaterials considered as scaffolds for bone tissue engineering, calcium phosphate-based ceramics have proven to be of great interest given their osteoconductivity and ability to "integrate" with the bone tissue. ${ }^{13,15,16,25-28}$ These characteristics can be further improved by varying the structural characteristics of the scaffolds. In a recent study of ours, we considered two HA bioceramics with identical microstructure but different macroporosity, pore size distribution, and pore interconnection pathway. The histological analysis of specimens at different times after in vivo implantation revealed in both materials a significant extent of bone matrix deposition, but we observed that porosity and pore interconnection of these scaffolds influenced the total amount of deposited bone, the pattern of blood vessel invasion, and finally the kinetics of the bone neoformation process. ${ }^{27}$

There are a number of sources of pluripotent mesenchymal cells potentially suitable for bone repair in association with porous ceramic scaffolds. ${ }^{28-32}$ The best characterized are those derived from the bone marrow stroma, which yields a mesenchymal stem/progenitor cell population from which differentiated cells of various connective tissues can be derived. Bone marrow-derived pluripotent mesenchymal stem cells (BMSCs) grown in vitro are capable of self-renewal for many generations without significant loss of their characteristics. ${ }^{33}$ They are also able to generate several distinct phenotypes including osteoblasts, chondrocytes, and adipocytes by relatively simple adjustments of culture conditions and biochemical supplements to which they are exposed.

We were the first to report the repair of large bone defects in humans using autologous in vitro expanded pluripotent mesenchymal cells associated to a porous ceramic. ${ }^{34}$ The study was based on promising results from earlier studies on large animal models and those already reported in the literature at the time we initiated our clinical study (late 1990s). ${ }^{18,21,35}$ Additional reports dealing with bone repair by a tissue engineering approach in large animal models have been published in the following years. ${ }^{17,28,29,33,36-39}$ In the present paper, we analyze the long-term outcome of a case series of four patients with large bone diaphysis defects and limited therapeutic alternatives. Initial clinical results at 1-2 years postsurgery were previously reported for three of these patients. ${ }^{34}$ The aim of the present work was to determine the durability of this type of implant in this first group of patients treated with this innovative tissue engineering method.

\section{MATERIALS AND METHODS}

\section{Patients}

The study protocol was approved by the ethical committees of the involved orthopedic centers. The patients, with age ranging from 16 to 41 years, possessed no neoplastic pathologies and were selected for this treatment after alternative, more "conventional" surgical therapies failed. The patients were informed of the nature of the treatment and gave their written consent. Essential information on the four patients is listed in Table 1.

Case 1. A 41-year-old woman presented a $4 \mathrm{~cm}$ shortening of the right leg and a severe osteoarthritis of the ankle and subtalar joints as the result of an ankle fracture complicated by an osteomyelitic process that occurred in 1992. At admission, the osteomyelitic process had completely resolved. The patient underwent arthrodesis of the right ankle and subtalar joints. To obtain leg lengthening, in the same surgical session, a tibia osteotomy was performed at the proximal diaphysis level and the bone was stabilized by an Ilizarov apparatus. The distraction of the tibia resulted in poor bone formation. After 10 months, a $4 \mathrm{~cm}$ gap between the two stumps with only a thin bone bridge located at the back was detectable by radiography. In May 1998, the patient was selected for the study.

Case 2. A 16-year-old girl presented a fracture of the left femoral neck and an exposed biosseous fracture of the left forearm as the result of a trauma. At admission, the patient 
Table 1. Cases

\begin{tabular}{lccccccc}
\hline $\begin{array}{l}\text { Case } \\
\text { number }\end{array}$ & Male/female & Age & $\begin{array}{c}\text { Affected } \\
\text { bone }\end{array}$ & $\begin{array}{c}\text { Size of } \\
\text { defect }(\mathrm{cm})\end{array}$ & $\begin{array}{c}\text { Type of scaffold } \\
(\text { 100\% HA) }\end{array}$ & $\begin{array}{c}\text { Fixator removal } \\
\text { (month) }\end{array}$ & $\begin{array}{c}\text { Last follow-up } \\
(\text { year })\end{array}$ \\
\hline 1 & Female & 41 & tibia & 4 & Finblock & 5.5 & 7 \\
2 & Female & 16 & ulna & 4 & Finblock & 6 & 6 \\
3 & Male & 22 & Humerus & 7 & Finblock & 8 & 7 \\
4 & Female & 29 & ulna & 6 & Engipore & 7 & 1.25 \\
\hline
\end{tabular}

underwent reduction of both ulna and radius fractures with Kirshner wires, together with surgical debridement and suture of the skin. Immobilization was obtained by a plaster cast. Two weeks later, the bone was stabilized by an Ilizarov forearm apparatus. After 1.5 months, the Ilizarov apparatus was removed due to osteomyelitis. In the same surgical session a sequestrectomy was performed at the distal diaphysis of the ulna. In December 1998, the osteomyelitis of the left forearm was completely healed with $4 \mathrm{~cm}$ bone loss at distal diaphysis of the ulna. In April 1999, the patient was selected for the study.

Case 3. A 22-year-old man presented a plurifragmented exposed fracture of the right humerus and of the elbow with an $8 \mathrm{~cm}$ bone loss in the distal third of the humerus diaphysis and a complete disarrangement of the elbow as the result of a car accident. The fracture was stabilized by an external fixator, leaving a gap of $7 \mathrm{~cm}$ at the distal humerus diaphysis. At the same time, the elbow arthrodesis was performed. No local infection was present. In June 1999, the patient was selected for the study.

Case 4. A 29-year-old woman presented multiple fractures (facial bones, right tibia, left femur, right wrist, left humerus) and an exposed biosseous fracture of the left forearm as a consequence of a car accident in 1999. In September 2004, the patient returned to the clinic with an ulnar preudoarthrosis and $6 \mathrm{~cm}$ bone loss, and was selected for the study.

\section{Isolation and culture of marrow-derived osteogenic progenitors}

Human BMSCs were obtained and cultured as described by Martin et al., with minor modifications within 36 hours from harvest. ${ }^{30}$ Briefly said, $20 \mathrm{~mL}$ samples of iliac crest marrow aspirates from each patient were washed with phosphate buffered saline (PBS), $\mathrm{pH}$ 7.2. Nucleated cells were counted, suspended in Coon's modified Ham's F12 medium supplemented with $10 \%$ fetal calf serum (FCS, Hyclone, Milano, Italy) and $1 \mathrm{ng} / \mathrm{mL}$ recombinant human basic fibroblast growth factor (FGF-2) (Austral Biologicals, San Ramon, $\mathrm{CA})$, and plated in $100 \mathrm{~mm}$ dishes at $4-5 \times 10^{6}$ nucleated cells per dish. Cultures were incubated at $37^{\circ} \mathrm{C}$ in a humidified atmosphere containing $95 \%$ air and $5 \%$ carbon dioxide $\left(\mathrm{CO}_{2}\right)$. Medium was changed after 2 days and then three times a week. When culture dishes became confluent (usually 3 weeks after the primary culture), the cells were detached with $0.05 \%$ trypsin and $0.01 \%$ EDTA, counted, centrifuged, and suspended in a small volume of culture medium.

For each bone marrow aspirate, the number of colonyforming units of fibroblasts (CFUf) present was tested by plating $100 \mu \mathrm{L}$ of aspirate in $10 \mathrm{~mm}$ Petri dish. After 15 days, cell cultures were washed with PBS, $\mathrm{pH} 7.2$, and stained with $1 \%$ methylene blue in borate buffer $(10 \mathrm{mM}, \mathrm{pH} 8.8)$ for $30 \mathrm{~min}$, followed by a washing with distilled water, for cell-colony counting.

\section{BMSC/bioceramics composite preparation}

The material selected as the scaffold for this study was a porous bioceramic based on 100\% HA (Finblock) produced and kindly provided by FinCeramica Srl, Faenza, Italy. Finblock has an average density of $1.26( \pm 0.16) \mathrm{g} / \mathrm{cm}^{3}$ and a total porosity of $60 \pm 5$ vol. $\%$. Parameters derived by an image analyzer system: mean diaphyseal wall thickness, $255.94 \pm 35.04 \mu \mathrm{m}$; mean pore diameter, $613.63 \pm$ $92.69 \mu \mathrm{m}$. In the case of patient no. 4 , the scaffold was a ceramic (Engipore), also manufactured by FinCeramica with the same chemistry as Finblock but with a higher porosity and a different pore structure. The average density of the Engipore scaffold is $0.72( \pm 0.09) \mathrm{g} / \mathrm{cm}^{3}$ and the total porosity is $80 \pm 3 \mathrm{vol} \%$. Parameters derived by an image analyzer system: mean diaphyseal wall thickness, $106.66 \pm$ $9.04 \mu \mathrm{m}$; mean pore diameter, $430.53 \pm 52.22 \mu \mathrm{m} .^{40}$

Bioceramic cylinders were prepared according to the size and shape of the bone gaps. Case 1 required a 4-cm-high cylinder with a diameter of $3 \mathrm{~cm}$ and a central canal of $0.5 \mathrm{~cm}$. Case 2 required a 4-cm-high cylinder with a diameter of $1 \mathrm{~cm}$ and a central canal of $0.2 \mathrm{~cm}$. Case 3 required a $7-\mathrm{cm}$-high cylinder with a diameter of $2.5 \mathrm{~cm}$ and a central canal of $0.5 \mathrm{~cm}$. Case 4 required a $6-\mathrm{cm}$-high cylinder with a diameter of $1 \mathrm{~cm}$ and a central canal of $0.3 \mathrm{~cm}$. Cylinders were dry sterilized for 4 hours at $200^{\circ} \mathrm{C}$.

In vitro expanded autologous BMSCs were suspended in Tissucol (Baxter AG, Wien, Austria) at a density of $2.0 \times$ $10^{7}$ cells/mL. The cell suspension was seeded onto the scaffolds by capillarity and incubated at $37^{\circ} \mathrm{C}$ for $60 \mathrm{~min}$. After addition of Thrombin (Baxter AG) to achieve fibrinogen polymerization, the ceramic-cell composite was incubated for $30 \mathrm{~min}$ at $37^{\circ} \mathrm{C}$ and then placed in a sterile container, filled with nutrient medium supplemented with $5 \%$ autologous 
serum, sealed and shipped to the orthopedic center via overnight delivery in a thermal box.

\section{Surgical procedure}

All patients were given general anesthesia and antibiotic prophylaxis. In case 1 the Ilizarov apparatus had been already positioned on the right tibia during the previous surgery. In case 2 an Ilizarov apparatus and in case 4 a monoaxial external fixator were positioned on the forearm during the surgical session. In case 3 the patient already possessed a monoaxial external fixator positioned when the elbow arthrodesis was performed; during the surgical session its mechanical stability was tested and improved. In the operating room, bone shafts were exposed and bone stumps regularized. The ceramic cylinders seeded with cells were positioned in the bone defects, soft tissues were apposed, and fascia and skin were closed following standard procedures.

\section{Patient evaluation}

Patients were hospitalized for 1 week after surgery. Clinical examination was carried out for signs of pain, swelling, and infection. Patients were evaluated every 30 days by soft radiography; a first computed tomography (CT) scan was performed 6-10 months after surgery. At longer followup periods, patients underwent clinical, radiographic, and CT evaluation every 12 months. In patient no. 3 , an angiographic evaluation was performed at 6.5 years follow-up.

\section{RESULTS}

Bone marrow stromal cells were isolated from the bone marrow of the patients based on their adherence to the plastic dish, expanded in vitro up to 12-14 cell doublings, and seeded onto the porous ceramic scaffolds. After in vitro expansion and before seeding onto the scaffold, the clonogenic potential of the cell population was tested. The determined CFUf value ranged between 50 and $2500 \mathrm{CFUf}$ per $\mathrm{mL}$.

No major complications occurred in the early or late postoperative periods in any of the patients, nor were major complaints reported by them. No significant signs of pain, swelling, or infection were observed at the implantation site.

The X-ray, CT scan, and angiographic evaluation of the patients are illustrated in figures 1-5. Callus formation was observed by radiography at the interface between the host bone and the HA cylinder after 1-2 months. Peri-implant bone formation was still undetectable by that time, but it became detectable during the following months. Progressively, the radiolucent line of the bone-implant interface disappeared. Consolidation between the implant and the host bone was completed 5 to 7 months after surgery. At this time, in case 1 and case 2, the external fixation apparatus were removed and the patients were allowed to gradually regain

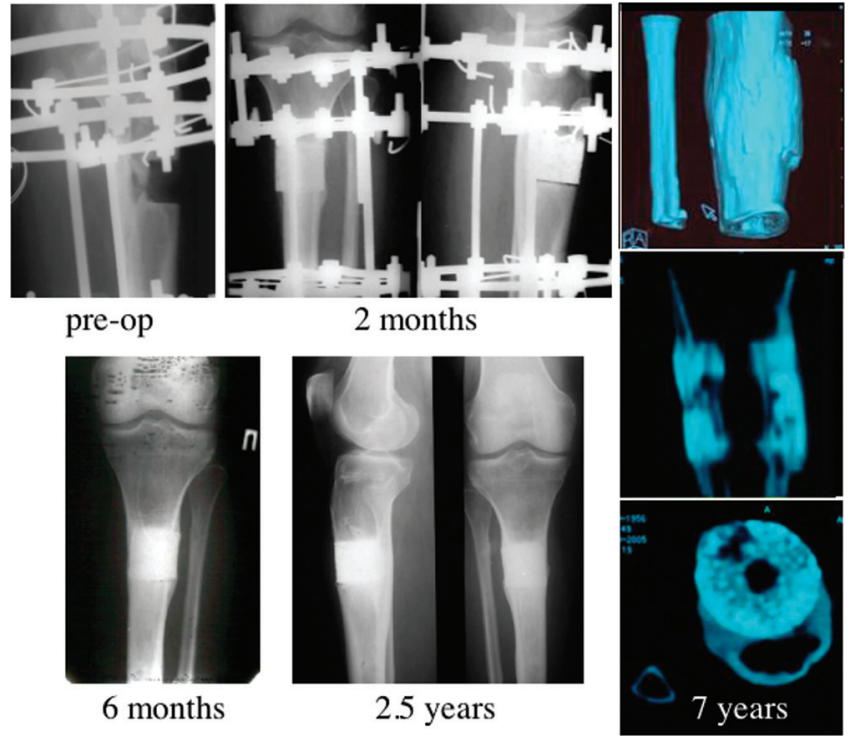

FIG. 1. Case 1. On the preoperative radiograph a 4-cm-long gap of the proximal tibia is shown. At 2 months, bone callus formation around the implant was evident, but the radiolucent line of the bone-implant interface was still detectable in the lateral view. At 6 months, formation of extensive callus and peri-implant bone with a good integration between the implant and the tibia was evident. At 2.5 years follow-up, complete bone-implant integration with no evidence of implant fractures was detected. CT scan analysis at 7 years demonstrated complete healing of the gap, presence of a medullary channel within the implant, and persistence of new bone formation within the bioceramic scaffold pores. The HA ceramic was still present. Color images available online at www.liebertpub.com/ten.

limb function. Six months after surgery, patient no. 1 was able to walk without support and with full weight bearing on the involved leg. Case 3 was the most complex from the biomechanical point of view. The Ilizarov apparatus was removed at 8 months after surgery and a custom-made cast was positioned. At this time, at the bone-implant interface, the ceramic was well integrated with the host bone as displayed by CT scan analysis that failed to demonstrate a radiolucent osteotomy line (Fig. 3, "8 months" panel). At 16-24 months, the graft incorporation was complete and the patient recovered a full function of the upper extremity (with the exclusion of the limitations created by the elbow arthrodesis) (Fig. 3, "16 months" panel). At the time of submitting this manuscript (i.e., at about 7 years follow-up), the patient is completely pain-free and satisfied with the treatment outcome. In patient no. 4, 7 months after surgery, loosening of the Hoffman fiches on proximal ulna was noted; therefore, the external fixator was removed and a plate with a contraposed cortical allograft was positioned on the arm to improve mechanical stability of the implant. During this second surgery, the implant was visualized and peri-implant bone formation was noted. Eight months after the first surgery, the patient was able to resume her activities. 

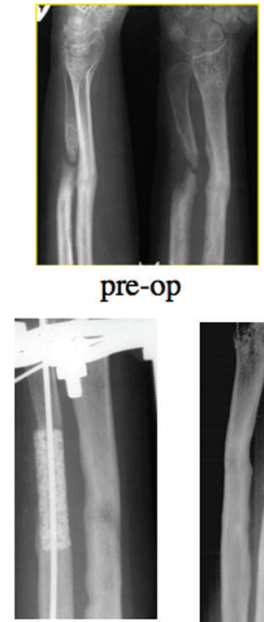

2 months

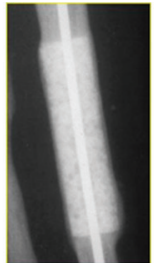

7 months

FIG. 2. Case 2. A $4 \mathrm{~cm}$ bone loss in the proximal ulna is evident on the preoperative radiograph. At 2 months, callus formation is observed by radiography at the interface between the host bone and the HA cylinder. Seven months after surgery a complete integration between the implant and the host bone together with extensive bone formation throughout the implant occurred. The K-wire was still positioned inside the medullary channel. At 2.5 years follow-up, the complete bone-implant integration was maintained and there was no evidence of implant fractures. CT scan analysis (2-D and 3-D reconstructions) at 6 years follow-up demonstrated a complete reconstruction of ulna with the presence of a medullary channel within the implant. No radiographic signs of bioceramic reabsorbtion were detectable. Color images available online at www .liebertpub.com/ten.

With time, the implants revealed a progressive appearance of cracks and fissures indicative of some bioceramic disintegration, while bone formation progressed and the implants were completely integrated to the host bone. In all patients at the last follow-up (6 to 7 years postsurgery in patients 1 to 3), a good integration of the implants was maintained. At the last radiographic and $\mathrm{CT}$ evaluation, the amount and the 3D structure of the implant ceramic scaffolds were essentially unaltered with regard to images of the same scaffolds taken immediately postsurgery.

Angiographic evaluation, performed 6.5 years postsurgery, indicated a vascularization of the grafted zone (Fig. 4, "6.5 years" panel).

\section{DISCUSSION}

The reconstruction of large bone segments still presents major biological and clinical problems. Several different therapeutic approaches, such as the Ilizarov bone transport, the transplant of autologous, allogeneic, and xenogeneic bone grafts, or the use of different biomaterial implants, have been proposed, but so far none have shown to be totally
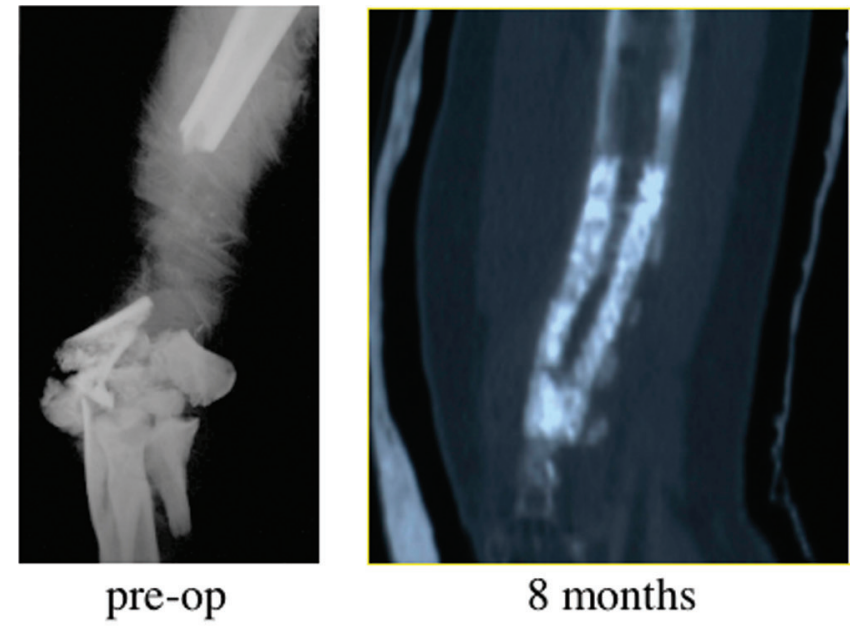



2 months

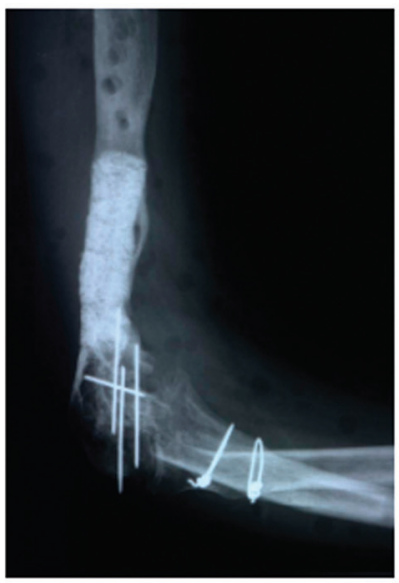

16 months
FIG. 3. Case 3. The preoperative radiograph shows a plurifragmental complex fracture of elbow and humerus with $7 \mathrm{~cm}$ bone loss in the distal humerus. At 2 months, an initial callus formation at the bone-implant interface was observed. At 8 months, CT scan 2-D analysis evidenced a callus formation along the HA cylinder. Neoformed bone was visible within the porous ceramics and a complete healing of the implant to the host bone with no radiolucent osteotomy line was evident. At 16 months, radiographs showed complete graft incorporation within the humerus. Color images available online at www.liebertpub.com/ten.

appropriate. We used a tissue engineering approach to treat patients with important bone loss and limited therapeutical alternatives. Initial clinical results at 1-2 years postsurgery were previously reported for three of these patients. ${ }^{34}$ Since our first description, only short-term follow-ups of few other patients treated with MSCs to repair long bone segmental defects have been reported in literature. ${ }^{41,42}$

In the present study, we describe the 6- to 7 years followup of our first three patients and of the fourth case treated more recently, in which a ceramic scaffold with the same chemistry but a different geometry was used. The findings reported here are the first to clinically support the long-term success of the bone tissue engineering approach. 

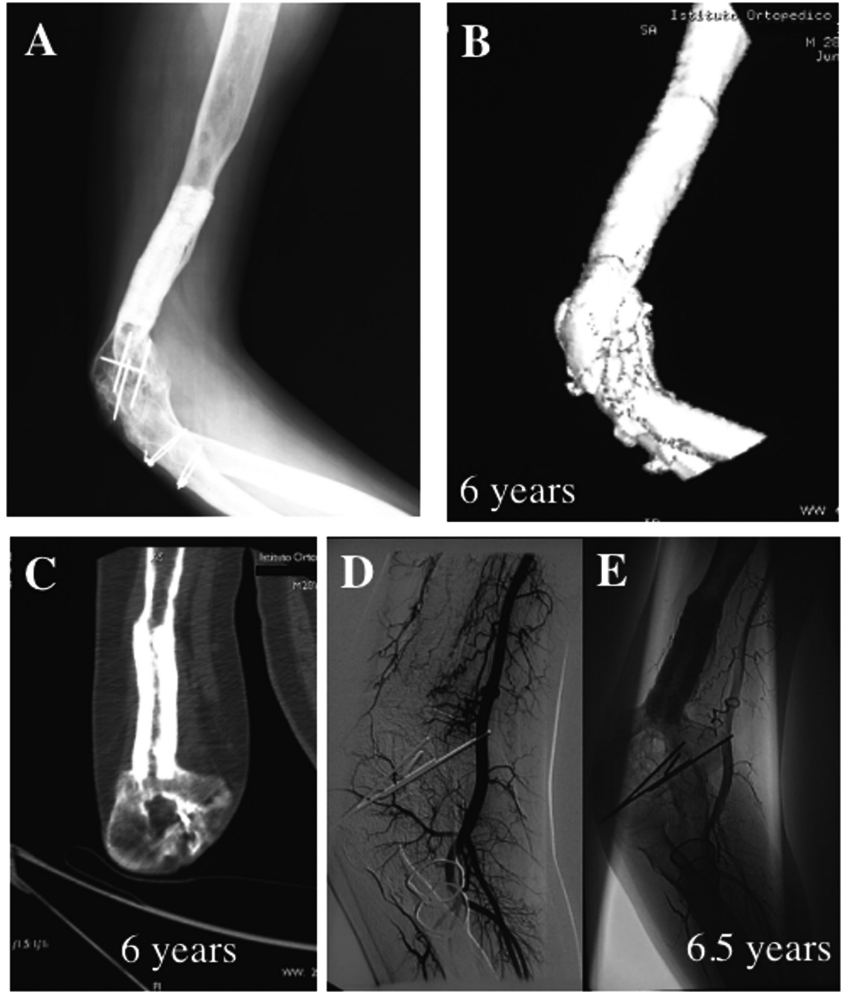

FIG. 4. Case 3. Analysis at 6 to 6.5 years follow-up. The radiographic evaluation at 6 years demonstrated a good integration of the implant within the host bone with complete healing of bone loss (A). This finding was confirmed by 3D and 2D CT scans at 6 years $(\mathbf{B}, \mathbf{C})$. No evidence of reabsorption of the bioceramic was present. An angiographic evaluation performed at 6.5 years follow-up showed new vessel formation with complete vascularization of the implant area (D, E).

For our study we selected clearly "challenging" patients, thus validating the effectiveness of the treatment. In case 1, the Ilizarov technique failed, while in cases 2, 3, and 4 the Ilizarov technique was to be avoided due to the need of radius resection and the high risk of nerve palsies and other complications. In cases 1,2 , and 4 , the bone loss was too extensive to permit implantation of biomaterials not loaded with cells, while an autograft, either vascularized or not vascularized, would have caused a serious donor site morbidity. In case 3, the particularly relevant bone substance loss made it virtually impossible to use any type of autograft. In cases 1 and 2, full functional recovery of the limbs was achieved 6.5 and 7 months after the implant surgery. The use of alternative methods would have implied longer recovery times. In cases 3 and 4 , the functional recovery took longer time due to the unfavorable mechanical situation of the grafted area. In fact, due to the insufficient mechanical properties of the initial fixation, a second surgery to obtain a more stable fixation was mandatory for patient recovery. Nevertheless, we consider the obtained results very encouraging because, by a more traditional approach, the expected recovery time would have been

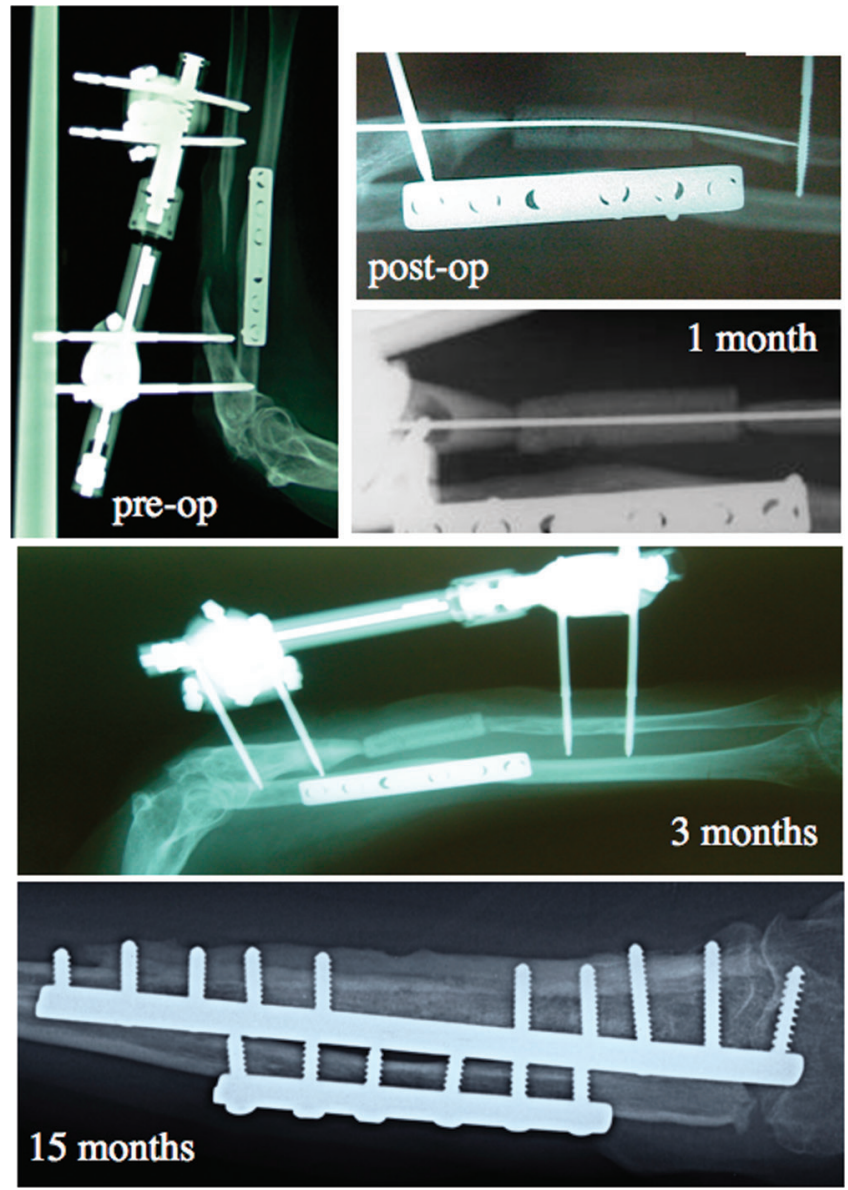

FIG. 5. Case 4 . On the preoperative radiograph a $6 \mathrm{~cm}$ bone loss in the distal ulna is visible. The implant was maintained in place by an external fixator and a K-wire positioned inside the medullary channel. Compared to the other cases, the implanted scaffold is less radiolucent due to the higher porosity of the biomaterial. At 1 month, an initial integration of the bone in the scaffold is evident. After 3 months, an initial callus formation and an integration of the implant were observed, but the radiolucent line at the boneimplant interface was still present. Radiographic evaluation at 15 months was difficult due to the presence of the metallic materials used for osteosynthesis and the cortical allograft. Nevertheless, a complete integration between the implant and the host bone, and bone formation throughout the implanted biomaterial were evident. Color images available online at www.liebertpub.com/ten.

at least $12-18$ months, in the most favorable hypothesis and in the absence of complications. ${ }^{6}$

It is to note that no control group (only scaffold and no cells) was used in our study. Selected patients were all extremely difficult clinical cases to treat and we wanted to guarantee all patients the best possible treatment and the highest bone regeneration capacity of the implant. The critical role of BMSCs in promoting bone repair by a tissue engineering approach was previously demonstrated by us in animal models. ${ }^{32}$ Anyway, the lack of a control group remains a drawback of our study. 
Tissue engineering strategies involving the use of BMSCs are based on the recognized degree of pluripotency of these cells. BMSCs can be easily isolated from iliac crest bone marrow aspirates. Nevertheless, a step of extensive in vivo expansion is required to obtain the number of cells necessary for reconstruction and repair of bone, given the low frequency of BMSCs in marrow aspirates. Number of cells per implant was chosen based on our previous experience with the ovine model. ${ }^{32}$

BMSCs in culture undergo progressive replicative aging and osteogenic differentiation, which are relevant to their successful clinical use, ${ }^{43}$ and this should be considered when designing cell-based therapies. Culture conditions that we defined and utilized to expand the BMSCs of the patients allowed us to obtain more than 20 cell doublings maintaining the cell osteogenic potential. The age of the patients selected for this study ranged between 16 and 41 years. Performing cell culture in strictly controlled culture conditions will be of particular relevance when expanding bone marrow stromal cells from older patients where the number of CFUf per $\mathrm{mL}$ of bone marrow aspirate is expected to be lower. ${ }^{44,45}$ Hernigou et al. have reported the use of fresh bone marrow directly injected into a nonunion lesion to obtain bone healing, and they have evaluated the number and concentration of progenitor cells in the marrow sample. ${ }^{46}$ Difference between the number of cells in the bone marrow directly injected into nonunion defects and the number of cells we have seeded onto the scaffold to be implanted depends on dissimilarity in the number of osteogenic cells (CFUf) present in these two cell populations.

BMSCs were seeded on $100 \%$ HA porous ceramics. These scaffolds presented good osteoconductivity, resulting in good functional recovery, but they were not resorbed after more than 7 years postimplantation. It is important to underline that, although no late fractures occurred in our patients, the permanence of biomaterial on long follow-up could compromise the biomechanics of the new bone. In addition, the high density of these scaffolds and, especially in the case of the scaffolds used to treat the first three patients, their relatively low porosity made radiographic follow-up rather difficult as the ceramic was masking the newly formed bone. The development of some secondgeneration resorbable ceramic scaffolds is therefore essential before a tissue engineering approach to bone repair could be widely applied in the clinical practice.

In a recent study we evaluated in an ovine model the performance of implants of resorbable ceramic based on silicon-stabilized tricalcium phosphate (Si-TCP) in promoting the repair of critical-sized bone defects. A progressive increase in new bone deposition into the pore of the scaffold together with a reduction of the scaffold ceramic occurred between 3 months and 1 year postsurgery. After 2 years the scaffold was essentially completely resorbed. In a second series of experiments, we compared the outcome of osteogenic cell-seeded implants versus unseeded implants in the same ovine model system. ${ }^{47}$ Only BMSC-loaded ceramics displayed a progressive scaffold resorption, coincident with new bone deposition. To investigate the coupled mechanisms of bone formation and scaffold resorption, X-ray computed microtomography $(\mu \mathrm{CT})$ and $\mu \mathrm{X}$-ray diffraction analysis were performed on BMSC-seeded small ceramic cubes implanted in immunodeficient mice for 2 or 6 months. ${ }^{48}$

In summary, based on the four patient outcomes some general conclusions can be made:

1. The pattern of the bone healing process in the patients was similar to the one described in the large animal model. ${ }^{18,19,28,29,32}$ The healing process can be considered to occur in four main steps: (a) bone formation on the outer surface of the implant, (b) bone formation in the inner cylinder canal, (c) formation of fissures and cracks in the implant body, and (d) bone formation in the bioceramic pores. Radiography and tomography showed that bone formation was far more prominent over the external surface and within the inner canal of the implants. This could be due to a higher density of loaded cells and/or a better survival of cells within the outermost portions of the HA bioceramics. Alternatively, the implanted cells could stimulate, via a paracrine or delayed paracrine mechanism, resident osteoprogenitor cells, located within the skeletal tissues at the resected ends. At the last follow-up, all patients, and in particular the three patients with a longer assessment, maintained a good integration of the implants and no late fractures were observed. No major complaints were reported by the patients, and no major adverse conditions were observed.

2. A high porosity and a high degree of interconnection between the pores are absolute requirements for vascularization of the implant and new bone formation. Vascularization of the implant is certainly critical for its survival and therefore its future stability. In some animal studies, new vascularization of the grafted area was obtained by a surgically created vascular pedunculus. ${ }^{49,50}$ In our clinical study, the presence of mesenchymal stem/progenitor cells was sufficient to induce vascularization of the grafted area. An angiographic examination was performed at the last followup in the most challenging case. The detection of new vessel growth into the implant confirmed the presence of a vital bone in the grafted area.

3. In agreement with previous studies that implanted HA, which is inert and remains within the body for extended periods, no visible signs of the biomaterial reabsorption were detected as long as 6-7 years postimplant. An ideal scaffold should provide an initial support for bone-forming cells and then it should be slowly reabsorbed at the same rate that the new bone is deposited inside the scaffold pores. Future similar studies should consider the use of such types of scaffolds. In recently performed animal trials, we established 
the feasibility of using implants of porous calcium phosphate-based resorbable scaffolds to obtain sitespecific new bone formation in a large-sized bone defect in a tibia sheep model. ${ }^{32,47}$

In conclusion, the aim of the present study was to analyze the long-term durability of bone regeneration achieved by a bone engineering approach. We observed progressive integration of the implants with the host bone, progressive new bone formation inside the bioceramic pores, and progressive vascular ingrowth. A good integration of the implants with the preexisting bone was maintained during all the follow-up periods and no major adverse conditions were observed.

In this pilot study, we used the tissue-engineered approach in very challenging cases with few therapeutical alternatives. It is our opinion that the tissue engineering approach for long bone reconstruction should be utilized more widely in the future, thus avoiding autologous bone harvesting or use of allogenic bone grafts. Presently, the most important bias of this method is represented by the low resorbability of porous HA bioceramics and in some cases by a low mechanical stability of the implant. Use of better bioresorbable constructs and application of a more stable fixation should help to avoid these problems. Eventually, controlled randomized clinical trials will have to clarify definitively the effectiveness and the cost/benefit superiority of the tissue engineering approach compared to other methods of bone reconstruction.

\section{ACKNOWLEDGMENTS}

The authors wish to thank FinCeramica Srl, Faenza, Italy, for providing samples of ceramic scaffolds before they were available on the market.

This work was supported by funds from the Italian Ministry of Instruction, University and Research (MIUR) and from the European and the Italian Space Agencies (ESA \& ASI).

We wish to thank Dr. A. Montaperto for technical assistance.

\section{REFERENCES}

1. Ilizarov, G.A. The tension-stress effect on the genesis and growth of tissues: Part II. The influence of the rate and frequency of distraction. Clin Orthop Relat Res 239, 263, 1989.

2. Goldstrohm, G.L., Mears, D.C., and Swartz, W.M. The results of 39 fractures complicated by major segmental bone loss and/or leg length discrepancy. J Trauma 24, 50, 1984.

3. Enneking, W.F., Eady, J.L., and Burchardt, H. Autogenous cortical bone grafts in the reconstruction of segmental skeletal defects. J Bone Joint Surg Am 62, 1039, 1980.

4. Taylor, G.I. The current status of free vascularized bone grafts. Clin Plast Surg 10, 185, 1983.

5. Sowa, D.T., and Weiland, A.J. Clinical applications of vascularized bone autografts. Orthop Clin North Am 18, 257, 1987.
6. Weiland, A.J., Moore, J.R., and Daniel, R.K. Vascularized bone autografts. Experience with 41 cases. Clin Orthop Relat Res 174, 87, 1983.

7. Laurie, S.W., Kaban, L.B., Mulliken, J.B., and Murray, J.E. Donor-site morbidity after harvesting rib and iliac bone. Plast Reconstr Surg 73, 933, 1984.

8. Stevenson, S. The immune response to osteochondral allografts in dogs. J Bone Joint Surg Am 69, 573, 1987.

9. Lord, C.F., Gebhardt, M.C., Tomford, W.W., and Mankin, H.J. Infection in bone allografts. Incidence, nature, and treatment. J Bone Joint Surg Am 70, 369, 1988.

10. Mankin, H.J., Gebhardt, M.C., and Tomford, W.W. The use of frozen cadaveric allografts in the management of patients with bone tumors of the extremities. Orthop Clin North Am 18, 275, 1987.

11. Alman, B.A., De Bari, A., and Krajbich, J.I. Massive allografts in the treatment of osteosarcoma and Ewing sarcoma in children and adolescents. J Bone Joint Surg Am 77, 54, 1995.

12. Heiple, K.G., Goldberg, V.M., Powell, A.E., Bos, G.D., and Zika, J.M. Biology of cancellous bone grafts. Orthop Clin North Am 18, 179, 1987.

13. Heise, U., Osborn, J.F., and Duwe, F. Hydroxyapatite ceramic as a bone substitute. Int Orthop 14, 329, 1990.

14. Oonishi, H. Orthopaedic applications of hydroxyapatite. Biomaterials 12, 171, 1991.

15. Sartoris, D.J., Holmes, R.E., and Resnick, D. Coralline hydroxyapatite bone graft substitutes: radiographic evaluation. J Foot Surg 31, 301, 1992.

16. Marcacci, M., Kon, E., Zaffagnini, S., Giardino, R., Rocca, M., Corsi, A., Benvenuti, A., Bianco, P., Quarto, R., Martin, I., Muraglia, A., and Cancedda, R. Reconstruction of extensive long-bone defects in sheep using porous hydroxyapatite sponges. Calcif Tissue Int 64, 83, 1999.

17. Ohgushi, H., Miyake, J., and Tateishi, T. Mesenchymal stem cells and bioceramics: strategies to regenerate the skeleton. Novartis Found Symp 249, 118, 2003.

18. Boyde, A., Corsi, A., Quarto, R., Cancedda, R., and Bianco, P. Osteoconduction in large macroporous hydroxyapatite ceramic implants: evidence for a complementary integration and disintegration mechanism. Bone 24, 579, 1999.

19. Mnaymneh, W., Malinin, T.I., Makley, J.T., and Dick, H.M. Massive osteoarticular allografts in the reconstruction of extremities following resection of tumors not requiring chemotherapy and radiation. Clin Orthop Relat Res 76, 1985.

20. Brittberg, M., Lindahl, A., Nilsson, A., Ohlsson, C., Isaksson, O., and Peterson, L. Treatment of deep cartilage defects in the knee with autologous chondrocyte transplantation. N Engl J Med 331, 889, 1994.

21. Krebsbach, P.H., Mankani, M.H., Satomura, K., Kuznetsov, S.A., and Robey, P.G. Repair of craniotomy defects using bone marrow stromal cells. Transplantation 66, 1272, 1998.

22. Matsumura, G., Hibino, N., Ikada, Y., Kurosawa, H., and Shin'oka, T. Successful application of tissue engineered vascular autografts: clinical experience. Biomaterials 24, 2303, 2003.

23. Dezawa, M., Hoshino, M., Nabeshima, Y., and Ide, C. Marrow stromal cells: implications in health and disease in the nervous system. Curr Mol Med 5, 723, 2005.

24. Brodie, J.C., and Humes, H.D. Stem cell approaches for the treatment of renal failure. Pharmacol Rev 57, 299, 2005. 
25. Elsinger, E.C., and Leal, L. Coralline hydroxyapatite bone graft substitutes. J Foot Ankle Surg 35, 396, 1996.

26. Ge, Z., Baguenard, S., Lim, L.Y., Wee, A., and Khor, E. Hydroxyapatite-chitin materials as potential tissue engineered bone substitutes. Biomaterials 25, 1049, 2004.

27. Mastrogiacomo, M., Scaglione, S., Martinetti, R., Dolcini, L., Beltrame, F., Cancedda, R., and Quarto, R. Role of scaffold internal structure on in vivo bone formation in macroporous calcium phosphate bioceramics. Biomaterials 27, 3230, 2006.

28. Kruyt, M.C., Dhert, W.J., Oner, C., van Blitterswijk, C.A., Verbout, A.J., and de Bruijn, J.D. Optimization of bone-tissue engineering in goats. J Biomed Mater Res B Appl Biomater 69, 113, 2004.

29. Zhu, L., Liu, W., Cui, L., and Cao, Y. Tissue-engineered bone repair of goat-femur defects with osteogenically induced bone marrow stromal cells. Tissue Eng 12, 423, 2006.

30. Martin, I., Muraglia, A., Campanile, G., Cancedda, R., and Quarto, R. Fibroblast growth factor-2 supports ex vivo expansion and maintenance of osteogenic precursors from human bone marrow. Endocrinology 138, 4456, 1997.

31. Noshi, T., Yoshikawa, T., Ikeuchi, M., Dohi, Y., Ohgushi, H., Horiuchi, K., Sugimura, M., Ichijima, K., and Yonemasu, K. Enhancement of the in vivo osteogenic potential of marrow/ hydroxyapatite composites by bovine bone morphogenetic protein. J Biomed Mater Res 52, 621, 2000.

32. Kon, E., Muraglia, A., Corsi, A., Bianco, P., Marcacci, M., Martin, I., Boyde, A., Ruspantini, I., Chistolini, P., Rocca, M., Giardino, R., Cancedda, R., and Quarto, R. Autologous bone marrow stromal cells loaded onto porous hydroxyapatite ceramic accelerate bone repair in critical-size defects of sheep long bones. J Biomed Mater Res 49, 328, 2000.

33. Cancedda, R., Mastrogiacomo, M., Bianchi, G., Derubeis, A., Muraglia, A., and Quarto, R. Bone marrow stromal cells and their use in regenerating bone. Novartis Found Symp 249, 133, 2003.

34. Quarto, R., Mastrogiacomo, M., Cancedda, R., Kutepov, S.M., Mukhachev, V., Lavroukov, A., Kon, E., and Marcacci, M. Repair of large bone defects with the use of autologous bone marrow stromal cells. N Engl J Med 344, 385, 2001.

35. Bruder, S.P., Jaiswal, N., Ricalton, N.S., Mosca, J.D., Kraus, K.H., and Kadiyala, S. Mesenchymal stem cells in osteobiology and applied bone regeneration. Clin Orthop Relat Res 355 Suppl, S247, 1998.

36. Xiao, Y., Qian, H., Young, W.G., and Bartold, P.M. Tissue engineering for bone regeneration using differentiated alveolar bone cells in collagen scaffolds. Tissue Eng 9, 1167, 2003.

37. Livingston, T., Ducheyne, P., and Garino, J. In vivo evaluation of a bioactive scaffold for bone tissue engineering. J Biomed Mater Res 62, 1, 2002.

38. Warren, S.M., Nacamuli, R.K., Song, H.M., and Longaker, M.T. Tissue-engineered bone using mesenchymal stem cells and a biodegradable scaffold. J Craniofac Surg 15, 34, 2004.

39. Logeart-Avramoglou, D., Anagnostou, F., Bizios, R., and Petite, H. Engineering bone: challenges and obstacles. J Cell Mol Med 9, 72, 2005.

40. Martinetti, R., Mastrogiacomo, M., Cancedda, R., and Peyrin, F. SEM and synchrotron radiation microtomography in the study of bioceramic scaffolds for tissue engineering applications. Biotechnol Bioeng, in press.
41. Kitoh, H., Kitakoji, T., Tsuchiya, H., Mitsuyama, H., Nakamura, H., Katoh, M., and Ishiguro, N. Transplantation of marrow-derived mesenchymal stem cells and platelet-rich plasma during distraction osteogenesis - a preliminary result of three cases. Bone 35, 892, 2004.

42. Vacanti, C.A., Bonassar, L.J., Vacanti, M.P., and Shufflebarger, J. Replacement of an avulsed phalanx with tissueengineered bone. N Engl J Med 344, 1511, 2001.

43. Banfi, A., Bianchi, G., Galotto, M., Cancedda, R., and Quarto, R. Bone marrow stromal damage after chemo/radiotherapy: occurrence, consequences and possibilities of treatment. Leuk Lymphoma 42, 863, 2001.

44. Galotto, M., Berisso, G., Delfino, L., Podesta, M., Ottaggio, L., Dallorso, S., Dufour, C., Ferrara, G.B., Abbondandolo, A., Dini, G., Bacigalupo, A., Cancedda, R., and Quarto, R. Stromal damage as consequence of high-dose chemo/radiotherapy in bone marrow transplant recipients. Exp Hematol 27, 1460, 1999.

45. Stenderup, K., Justesen, J., Clausen, C., and Kassem, M. Aging is associated with decreased maximal life span and accelerated senescence of bone marrow stromal cells. Bone 33, 919, 2003.

46. Hernigou, P., Mathieu, G., Poignard, A., Manicom, O., Beaujean, F., and Rouard, H. Percutaneous autologous bonemarrow grafting for nonunions. Surgical technique. J Bone Joint Surg Am 88 Suppl 1 Pt 2, 322, 2006.

47. Mastrogiacomo, M., Corsi, A., Francioso, E., Di Comite, M., Monetti, F., Scaglione, S., Favia, A., Crovace, A., Bianco, P., and Cancedda, R. Reconstruction of extensive long bone defects in sheep using resorbable bioceramics based on silicon stabilized tricalcium phosphate. Tissue Eng 12, 1261, 2006.

48. Mastrogiacomo, M., Papadimitropoulos, A., Cedola, A., Peyrin, F., Giannoni, P., Pearce, S.G., Alini, M., Giannini, C., Guagliardi, A., and Cancedda, R. Engineering of bone using bone marrow stromal cells and a silicon-stabilized tricalcium phosphate bioceramic: evidence for a coupling between bone formation and scaffold resorption. Biomaterials 28, 1376, 2007. Epub 2006 Nov 28.

49. Nakasa, T., Ishida, O., Sunagawa, T., Nakamae, A., Yasunaga, Y., Agung, M., and Ochi, M. Prefabrication of vascularized bone graft using a combination of fibroblast growth factor-2 and vascular bundle implantation into a novel interconnected porous calcium hydroxyapatite ceramic. J Biomed Mater Res A 75, 350, 2005.

50. Akita, S., Tamai, N., Myoui, A., Nishikawa, M., Kaito, T., Takaoka, K., and Yoshikawa, H. Capillary vessel network integration by inserting a vascular pedicle enhances bone formation in tissue-engineered bone using interconnected porous hydroxyapatite ceramics. Tissue Eng 10, 789, 2004.

Address reprint requests to: Dott.ssa Elizaveta Kon

Laboratorio di Biomeccanica Istituti Ortopedici Rizzoli Via di Barbiano, 1/10 40136 Bologna Italy

E-mail: E.Kon@biomec.ior.it 
